OPEN ACCESS

Edited by: Alex Olvera, IrsiCaixa, Spain

Reviewed by:

César Bernardo Gutiérrez Martín, Universidad de León, Spain Xiangru Wang,

Huazhong Agricultural University,

China

${ }^{*}$ Correspondence: Martin Faldyna faldyna@vri.cz

Specialty section:

This article was submitted to Vaccines and Molecular Therapeutics, a section of the journal

Frontiers in Immunology

Received: 29 November 2020 Accepted: 06 April 2021

Published: 22 April 2021

Citation:

Matiašková K, Kavanová L, Kulich P, Gebauer J, Nedbalcová K, Kudláčková $H$, Tesařk $R$ and Faldyna $M$ (2021) The Role of Antibodies Against the Crude Capsular Extract in the Immune Response of Porcine Alveolar Macrophages to In Vitro Infection of Various Serovars of Glaesserella (Haemophilus) parasuis.

Front. Immunol. 12:635097. doi: 10.3389/fimmu.2021.635097

\section{The Role of Antibodies Against the Crude Capsular Extract in the Immune Response of Porcine Alveolar Macrophages to In Vitro Infection of Various Serovars of Glaesserella (Haemophilus) parasuis}

Katarína Matiašková ${ }^{1}$, Lenka Kavanová ${ }^{1}$, Pavel Kulich ${ }^{2}$, Jan Gebauer ${ }^{1}$, Kateřina Nedbalcová ${ }^{1}$, Hana Kudláčková ${ }^{1}$, Radek Tesařik $^{1}$ and Martin Faldyna ${ }^{1,3 *}$

\footnotetext{
1 Department of Infectious Diseases and Preventive Medicine, Veterinary Research Institute, Brno, Czechia, ${ }^{2}$ Department of Pharmacology and Toxicology, Veterinary Research Institute, Brno, Czechia, ${ }^{3}$ Department of Infectious Diseases and Microbiology, University of Veterinary Sciences, Brno, Czechia
}

In Glässer's disease outbreaks, Glaesserella (Haemophilus) parasuis has to overcome the non-specific immune system in the lower respiratory tract, the alveolar macrophages. Here we showed that porcine alveolar macrophages (PAMs) were able to recognize and phagocyte $G$. parasuis with strain-to-strain variability despite the presence of the capsule in virulent (serovar 1, 5, 12) as well in avirulent strains (serovar 6 and 9). The capsule, outer membrane proteins, virulence-associated autotransporters, cytolethal distending toxins and many other proteins have been identified as virulence factors of this bacterium. Therefore, we immunized pigs with the crude capsular extract (CCE) from the virulent $G$. parasuis CAPM 6475 strain (serovar 5) and evaluated the role of the anti-cCE/postvaccinal lgG in the immune response of PAMs to in vitro infection with various $G$. parasuis strains. We demonstrated the specific binding of the antibodies to the CCE by Westernblotting assay and immunoprecipitation as well as the specific binding to the strain CAPM 6475 in transmission electron microscopy. In the CCE, we identified several virulenceassociated proteins that were immunoreactive with $\mathrm{lgG}$ isolated from sera of immunized pigs. Opsonization of $G$. parasuis strains by post-vaccinal IgG led to enhanced phagocytosis of $G$. parasuis by PAMs at the first two hours of infection. Moreover, opsonization increased the oxidative burst and expression/production of both pro- and anti-inflammatory cytokines. The neutralizing effects of these antibodies on the antioxidant mechanisms of $G$. parasuis may lead to attenuation of its virulence and pathogenicity in vivo. Together with opsonization of bacteria by these antibodies, the host may eliminate $G$. parasuis in the infection site more efficiently. Based on these results, the crude capsular extract is a vaccine candidate with immunogenic properties.

Keywords: Haemophilus parasuis, Glaesserela parasuis, capsule, antibodies, porcine alveolar macrophages, reactive oxygen species, catalase, antioxidants 


\section{INTRODUCTION}

Glaesserella (Haemophilus) parasuis, a gram-negative bacterium from the family Pasteurellaceae, is a commensal organism of the upper respiratory tract of swine (1). Under certain conditions, it is able to invade host and cause severe systemic disease (Glässer's disease) with high morbidity and mortality (2). To date, 15 serovars of different virulence have been defined (3) but some differences in virulence have been observed also among strains of the same serovar indicating the presence of other virulence factors (4). In Glässer's disease outbreaks, G. parasuis has to overcome the first line of defense in the lower respiratory tract of pigs, the porcine alveolar macrophages (PAMs) (2, 5). PAMs recognize the cell structures on the surface of the bacterium, phagocyte, lyse it and produce pro-inflammatory and antiinflammatory cytokines and chemokines to attract the leucocytes to the infection site (6). Differences in phagocytosis observed in various $G$. parasuis strains may be caused by presence of the capsule, different structure of the capsule polysaccharides, phagocytosis resistance mechanism or other virulence factors like virulence associated autotransporters (VtaA) or transferrin binding protein B (TbpB) (4, 7-10).

Phagocytosis may be more effective when the bacterium is opsonized by a complement or by antibodies. Since it has been known that $G$. parasuis is resistant to serum complement (11) and bacterial capsule interferes with complement deposition (12), opsonization of the bacterium would be more effective by antibodies (7). Based on these facts, we decided to prepare the crude capsular extract (cCE) from the virulent G. parasuis strain that contains capsular polysaccharides and also proteins associated with the virulence of the bacterium (13) and thus antibodies against this antigens may opsonize the bacterium more efficiently. The protective role of antibodies against $G$. parasuis infection was proved in numerous in vivo experiments (14-16). In our previous study, the cCE was highly immunogenic and mice immunized with the $\mathrm{CCE}$ were partially protected against the challenge with various G. parasuis strains. Moreover, mice immunized with the cCE decreased bacterial load in the target tissues comparing to the non-immunized mice (13). The objective of the present study was to determine the role of antibodies against this capsular extract in the immune response of PAMs to in vitro infection with various $G$. parasuis strains opsonized by these antibodies. We hypothesized that these antibodies may facilitate phagocytosis of G. parasuis leading to higher production of reactive oxygen species (ROS) as well as to higher production of pro-inflammatory and antiinflammatory cytokines with subsequent more effective destruction of the bacterium.

\section{MATERIALS AND METHODS}

\section{Bacterial Strains}

The reference strains of G. parasuis kindly provided by Université de Montréal (Canada) used in this study were the following: strain No.4 of serovar (s.) 1 (HP1), strain 131 of s. 6 (HP6), strain D74 of s. 9 (HP9) and strain H425 of s. 12 (HP12). We used also the field strain CAPM 6475 of serovar 5 (HP5) which did originate from the brain of a pig with meningitis (14). Kielsten and Rapp-Gabrielson (3) determined the virulence of the serovar reference strains, whereby serovars 6 and 9 are nonvirulent and serovars 1, 5 and 12 are virulent. Strains were grown on chocolate agar plates (LabmediaServis) at $37^{\circ} \mathrm{C}$ for 18 hours.

\section{Capsule Detection of G. parasuis Strains}

Capsule was detected using the negative staining method. Each strain of $G$. parasuis used in the study was cultivated on chocolate agar overnight, resuspended in a phosphate-buffered saline (PBS, ThermoFisher Scientific), transported to the watch glasses and covered with a copper grid (300 OLD Mesh, Agar Scientific) coated with Formvar membrane (Sigma-Aldrich) and carbon (Agar Scientific). After 5 minutes, the grid was removed and residual water was dried out with a filter paper. Subsequently, a drop of $2 \%$ aqueous ruthenium red (SigmaAldrich) was added to the bacteria culture on the grid for a few seconds. After drying of stain residues with filtration paper, the sample was observed by the transmission electron microscope Philips 208 S MORGAGNI (FEI) at a magnification of $2,800-18,000 \times$ and at accelerating voltage of $80 \mathrm{kV}$.

\section{Preparation Method of the Crude Capsular Extract}

The preparation method of the crude capsular extract (cCE) obtained from G. parasuis strain CAPM 6475 by methanol extraction was described in our previous study (13). Briefly, the overnight culture of $G$. parasuis resuspended in D-PBS was incubated in a water bath at $60^{\circ} \mathrm{C}$ for $1 \mathrm{~h}$ and formaldehyde was added to the bacterial suspension to a final concentration of $0.2 \%$ (v/v). After centrifugation at $9,500 \times \mathrm{g}$ at $4^{\circ} \mathrm{C}$ for $1 \mathrm{~h}$, the supernatant was concentrated to $1 / 50$ of the volume using a VIVAFLOW 200 filter 5,000 MWCO PES (Sartorius Stedim Biotech) and three concentrate volumes of methanol (PENTA) and sodium acetate (PENTA) to $1 \%(\mathrm{w} / \mathrm{v})$ were added. After $24 \mathrm{~h}$, the supernatant was filtered with VIVAFLOW 200 filter 0.2 $\mu \mathrm{m}$ PES (Sartorius Stedim Biotech) and three concentrate volumes of acetone (PENTA) were added. After $36 \mathrm{~h}$ of the precipitate gravity settling, supernatant was discarded and the precipitate was resuspended in an aqua pro injection and stored at $-20^{\circ} \mathrm{C}$. The concentration of proteins in the $\mathrm{CCE}$ was determined with a Pierce ${ }^{\mathrm{TM}}$ BCA Protein Assay Kit (ThermoFisher Scientific) according to the manufacturer's instructions. The concentration of polysaccharides was determined using Phenol-Sulfuric acid method (PSA) with glucose as a standard for calibration. The samples and glucose (PENTA) were dispensed into the 96-well plates and $75 \mu \mathrm{L}$ of a sulfuric acid (PENTA) was added in each well. After 15 min of incubation at $90^{\circ} \mathrm{C}$ in the dark, $15 \mu \mathrm{L}$ of $5 \%$ phenol water solution was added to each well. After $5 \mathrm{~min}$ of shaking, the absorbance was measured at $488 \mathrm{~nm}$ using a multireader Synergy H1 (BioTek).

\section{Antibodies Isolation}

Sixteen pigs included in the experiment were negatively tested for presence of anti-G. parasuis antibodies before the immunization with the cCE by commercial ELISA kit (Swinecheck HPS ELISA 
test, Biovet). Animals were intramuscularly immunized with two 2 $\mathrm{mL}$ doses of the cCE and Montanide ISA $201 \mathrm{VG}$ adjuvant (Seppic) in the ratio of 1:1 at 21-day intervals. The polysaccharide and protein concentration in one dose was $0.5 \mathrm{mg}$ and $0.7 \mathrm{mg}$, respectively. Blood samples obtained from pigs before the immunization (negative sera) and at 14 days after the second immunization (positive sera) were centrifuged at $830 \times \mathrm{g}$ at $21^{\circ} \mathrm{C}$ for $15 \mathrm{~min}$, sera were collected, mixed together (negative or positive pooled serum) and inactivated at $56^{\circ} \mathrm{C}$ for $30 \mathrm{~min}$. The $\mathrm{IgG}$ antibodies were then purified from the negative or positive pooled serum using the column with Protein A (Protein A IgG Purification Kit, Thermo Scientific) according to the manufacturer's instructions. For in vitro tests, the concentration of IgG isolated from the positive pooled serum (post-vaccinal/anticCE IgG) was measured with a Pierce ${ }^{\mathrm{TM}}$ BCA Protein Assay Kit. All procedures involving animals were approved by the Branch Commission for Animal Welfare of the Ministry of Agriculture of the Czech Republic (approval protocol No. MZe 1704).

\section{Detection of the Antibodies Against the CCE}

The antibody titer against the CCE in the negative or the positive sera of pigs was determined by in house indirect enzyme-linked immunosorbent assay (ELISA) (13). The cCE antigen was dissolved in a carbonate-bicarbonate buffer $(\mathrm{pH} 9.6)$ in a concentration of $1 \mu \mathrm{g} / \mathrm{mL}$ that was subsequently dispensed (100 $\mu \mathrm{L} /$ well) into the wells of the Nunc MaxiSorp ${ }^{\circledR}$ flatbottom 96-well polystyrene microtiter plate (ThermoFisher Scientific). After the overnight incubation at $4^{\circ} \mathrm{C}$, the wells were rinsed four times with $300 \mu \mathrm{L}$ of diluting solution containing PBS with $0.05 \%$ Tween-20 (PBS-T). The wells were then blocked with $0.5 \%$ casein and $10 \%$ sucrose (in $250 \mu \mathrm{L}$ of PBS per well) for $30 \mathrm{~min}$ at a room temperature (RT). The tested sera were prediluted $300 \times$ in a solution of PBS with $0.05 \%$ Tween and $0.5 \%$ casein hydrolysate and dispensed to wells $(100 \mu \mathrm{L}$ per well). After the incubation of the plate for one hour at RT, the wells were rinsed four times with PBS-T. $100 \mu \mathrm{L}$ of goat antiporcine IgG labelled with horseradish peroxidase (Bethyl Laboratories) prediluted 1:30 000 in PBS with $0.05 \%$ Tween and $0.5 \%$ casein hydrolysate was added to wells and incubated for another $1 \mathrm{~h}$ at RT. Afterwards, the plate was rinsed four times with PBS-T and $100 \mu \mathrm{L}$ of TMB-Complete 2 solution (TestLine) was added into each well. The reaction was stopped after $15 \mathrm{~min}$ of incubation at RT by adding $50 \mu \mathrm{L}$ of $1 \mathrm{M}$ sulfuric acid into each well. The absorbance was read at $450 \mathrm{~nm}$ using the multidetection microplate reader Synergy H1 (BioTek).

\section{The Specificity of the Antibodies Against the CCE}

To prove the specificity of the antibodies against the cCE, Western-blotting, immunoprecipitation with mass spectrometry and transmission electron microscopy (TEM) were performed.

In the Western-blotting, the cCE antigen was resolved on $12.5 \%$ SDS-PAGE and blotted on PVDF membrane (Amersham). The membrane was then incubated overnight at $4^{\circ} \mathrm{C}$ in blocking solution containing $1 \%$ casein in PBS with $0.05 \%$
Tween-20 (PBS-T, Serva). The membranes were incubated with the positive or negative pooled serum or with the isolated IgG from these sera (diluted $100 \times$ in PBS-T with $1 \%$ casein) for $1 \mathrm{~h}$ at RT. The membranes were then washed in PBS-T and incubated with goat anti-pig HRP-conjugated IgG (Bethyl Laboratories) for another $1 \mathrm{~h}$ at RT. Secondary antibodies were diluted 1:1000 in PBS-T. Specific protein bands were visualized with 3, 3'diaminobenzidine (Sigma-Aldrich).

Immunoprecipitation protocol was established using Pierce Crosslink Immunoprecipitation Kit (Thermo scientific) according to manufacturer's manual. Briefly, $50 \mu \mathrm{g}$ of isolated IgG from positive or negative sera were bound to Protein A/G on agarose resin. After washing steps, bound antibodies were crosslinked with DSS (disuccinimidyl suberate) dissolved in DMSO to make a covalent bond. $2 \mathrm{mg}$ of cCE was pre-cleared using the control agarose resin to prevent unspecific binding to agarose itself. Immunoprecipitation of $1 \mathrm{mg}$ of pre-cleared $\mathrm{cCE}$ with isolated IgG took place at $4^{\circ} \mathrm{C}$ overnight with gentle mixing. After washing steps, specifically bound bacterial proteins were eluted with low $\mathrm{pH}$ elution buffer and analyzed by mass spectrometry.

\section{Immunoelectron Microscopy}

Immunoelectron microscopy was performed according to Huebner et al. (17). The overnight culture of G. parasuis CAPM 6475 cultivated on the chocolate agar was resolved in 1 $\mathrm{mL}$ of PBS and centrifuged at 4,000 $\times \mathrm{g}$ for $3 \mathrm{~min}$. The bacterial pellet was then washed three times and resuspended in PBS. Drops $(30 \mu \mathrm{L})$ of the bacterial culture were placed on Parafilm and a Formvar coated nickel grids (300 OLD Mesh, Agar Scientific) were placed on each drop for $1 \mathrm{~min}$. The grids were then blocked by placement on drops $(20 \mu \mathrm{L})$ of $0.5 \%$ fishskingelatin in PBS containing $0.1 \%$ Tween-20 (Serva) for $5 \mathrm{~min}$. The grids were subsequently incubated on a drop $(20 \mu \mathrm{L})$ of 1:50 diluted positive or negative pooled serum. After $20 \mathrm{~min}$ of incubation at RT, the grids were washed twice with PBS-T and placed on drops $(20 \mu \mathrm{L})$ of 1:10 diluted Protein A-20 nm colloidal gold (Sigma-Aldrich) for $20 \mathrm{~min}$ at RT. Afterwards, the grids were washed four times with distilled water and observed by transmission electron microscope Philips 208S MORGAGNI (FEI) at a magnification of 7,500 $\times$ and at accelerating voltage of $80 \mathrm{kV}$.

\section{LC-MS/MS Analysis of the CCE and Immunocomplexes}

By mass spectrometry, the protein content in the $\mathrm{CCE}$ and proteins of $\mathrm{cCE}$ bounded to the isolated IgG were analyzed. Fifty micrograms of proteins for each of four cCE replicates (four cCE preparations) were analyzed. For identification of proteins after immunoprecipitation, the whole elution fraction (without protein concentration determination) was used. All samples were prepared using FASP (filter-aided sample preparation) method (18). Every sample was washed 6 times in $8 \mathrm{M}$ urea (Serva) in Vivacon 500 centrifugal tube (Sartorius Stedim) with 10,000 MWCO membrane filter. Dithiothreitol (10 mM, SigmaAldrich) and iodoacetamide (50 mM, Serva) in $25 \mathrm{mM}$ TEAB buffer (triethylammonium bicarbonate, Sigma-Aldrich) were used 
for reduction and alkylation, respectively. Proteins were then digested with trypsin (Promega) in 1:50 ratio, for one hour at $37^{\circ} \mathrm{C}$ and then overnight at $25^{\circ} \mathrm{C}$. After centrifugation, the eluate with digested peptides was evaporated (DNA120 SpeedVac, Thermo Savant, USA), peptide pellet was resuspended in $0.1 \%$ aqueous formic acid (Sigma- Aldrich) which serves as a mobile phase for liquid chromatography (UltiMate 3000 RSLCnano, Thermo Scientific). For separation and elution of peptides, 2hour gradient with increasing concentration of acetonitrile $(0.1 \%$ formic acid in acetonitrile, Sigma-Aldrich) at a flow rate of $300 \mathrm{nl} /$ min was used. Peptides were separated on a $15 \mathrm{~cm}$ column (Acclaim PepMap RSLC C18, $2 \mu \mathrm{m}, 100$ A, $75 \mu \mathrm{m}$ I.D., Thermo Scientific). uHPLC was connected to EASY-spray ion source and Orbitrap Velos Pro mass spectrometer (Thermo Scientific). A survey scan over $\mathrm{m} / \mathrm{z}$ range 390-1,700 was used to identify protonated peptides with charge states of at least 2 , which were automatically selected for data- dependent MS/MS analysis and fragmented by collision with helium gas. Ten fragment mass spectra after each full scan were recorded. Measured spectra were then searched using Proteome Discoverer (version 1.4, Thermo Scientific) with Sequest HT as a searching algorithm. Oxidation of $\mathrm{M}$, deamidation of $\mathrm{N}$ and $\mathrm{Q}$ as a dynamic, and carbamidomethylation of $\mathrm{C}$ as a static modification was used. Precursor and fragment mass tolerances were set up as $10 \mathrm{ppm}$ and $0.5 \mathrm{Da}$, respectively. Uniprot database for Glaesserella strain (from 2016/02) was used in Sequest HT. Only peptides with a false discovery rate less than 0.01 were considered as well identified and only proteins with at least two unique well identified peptides were included into results. Quantity of identified proteins is expressed by the PSM number (peptide spectrum matches). The ratio between vaccinated and control sample is calculated from the area under the curve of the chromatographic peak detected by mass spectrometer.

\section{Porcine Alveolar Macrophages Preparation}

Porcine alveolar macrophages were obtained immediately after euthanasia of six clinically healthy 8-weeks-old pigs free of anti- $G$. parasuis antibodies (Swinecheck HPS ELISA test, Biovet) by bronchoalveolar lavage as previously described (19). Euthanasia was performed by intravenous injection of the anesthetic T61 (Intervet International B.V.) in a dose recommended by the manufacturer $(5 \mathrm{~mL} / \mathrm{kg}$ of body weight). All procedures involving animals were approved by the Branch Commission for Animal Welfare of the Ministry of Agriculture of the Czech Republic (approval protocol No. MZe 1487). After lavage, PAMs were washed three times with a calcium-magnesium free Dulbecco's phosphate-buffered saline (D-PBS; Lonza) and aliquots with isolated PAMs were frozen in medium containing 75\% RPMI1640 (Sigma-Aldrich), 20\% fetal bovine serum (FBS; PAA Laboratories), and 5\% dimethyl sulfoxide (DMSO; Sigma-Aldrich) and stored in a liquid nitrogen until use. Before each experiment, PAMs were thawed in a water bath at $37^{\circ} \mathrm{C}$. The cell viability after freezing and thawing was determined by the BD FACSAriaTM Fusion flow cytometer and was greater than 90\%. The cells were washed with Dulbecco's Modified Eagle's Medium (DMEM, Invitrogen), centrifuged at $1,100 \times \mathrm{g}$ and $10^{\circ} \mathrm{C}$ for $10 \mathrm{~min}$ and resuspended with DMEM supplemented with 10\% FBS and 1\% antibiotics (Antibiotic Antimycotic Solution $100 \times$ : 10,000 units penicillin, $10 \mathrm{mg}$ streptomycin, and $25 \mu \mathrm{g}$ amphotericin B per $\mathrm{mL}$; Sigma-Aldrich). PAMs were then dispensed into 24-well culture plates (Biotech) at a concentration of $4 \times 10^{5}$ cells in $1 \mathrm{~mL}$ per well or in case of chemiluminescence assay into Nunc-Immuno ${ }^{\mathrm{TM}}$ MicroWell $^{\mathrm{TM}}$ 96-well polystyrene plates (Sigma-Aldrich) at a concentration of $1 \times 10^{5}$ cells in $0.2 \mathrm{~mL}$ per well and incubated overnight at $37^{\circ} \mathrm{C}, 5 \% \mathrm{CO}_{2}$.

\section{Infection of PAMs}

After overnight incubation at $37^{\circ} \mathrm{C}$ on chocolate agar plates, bacteria were harvested by centrifugation at $4,000 \times \mathrm{g}$ for 3 min following resuspending in $1 \mathrm{~mL}$ of D-PBS, washed twice with D-PBS and resuspended in D-PBS by adjusting turbidity to the density equivalent to a $2.5 \mathrm{McF}$ arland standard (DENSI-LA-METER II, ErbaLachema). To determine the final bacterial concentration after washing, ten-fold dilutions were plated on chocolate agars. The concentration of the final inoculum was $1 \times 10^{9} \mathrm{CFU} / \mathrm{mL}$.

Before the infection, $4 \times 10^{6} \mathrm{CFU}$ of every bacterial strain was incubated with $180 \mu \mathrm{g}$ of the isolated post-vaccinal IgG or without IgG for $30 \mathrm{~min}$ at $37^{\circ} \mathrm{C}$.

After overnight incubation of PAMs in 24 -well plates $\left(37^{\circ} \mathrm{C}\right.$, $5 \% \mathrm{CO}_{2}$ ), the non-adherent PAMs were washed with DMEM supplemented with $10 \%$ FBS. Thereafter, duplicate wells with PAMs were inoculated with G. parasuis strains pre-incubated with/without the isolated post-vaccinal IgG at a multiplicity of infection (MOI) of 10 in DMEM supplemented with 10\% FBS. The infected and non-infected (only with DMEM) cells incubated at $37^{\circ} \mathrm{C}$ and $5 \% \mathrm{CO}_{2}$ for different time points were then used in various assays (described in the chapters below).

\section{Phagocytosis Assay and Survival of Bacteria}

Bacteria pre-incubated with/without the post-vaccinal IgG were allowed to uptake by PAMs for $0.5,1,2$ or $5 \mathrm{~h}$. After incubation, wells were washed twice and incubated with DMEM supplemented with $10 \% \mathrm{FBS}$ and $5 \mathrm{mg} / \mathrm{mL}$ of gentamicin to kill the extracellular bacteria for additional $30 \mathrm{~min}$ at $37^{\circ} \mathrm{C}, 5 \%$ $\mathrm{CO}_{2}$. This concentration of gentamicin did not affect PAMs and was bactericidal to all strains. After $30 \mathrm{~min}$ with gentamicin, wells were washed twice with D-PBS and PAMs were lysed with $1 \%$ Saponin (Sigma-Aldrich). Bacteria were counted by plating ten-fold dilutions on chocolate agar plates.

To find out whether internalized bacteria survive inside the macrophages, PAMs were incubated with opsonized or nonopsonized bacteria for $2 \mathrm{~h}$, washed twice with DMEM with $10 \%$ FBS and then gentamicin $(5 \mathrm{mg} / \mathrm{mL})$ was added to eliminate the extracellular bacteria. After $30 \mathrm{~min}$ at $37^{\circ} \mathrm{C}$ and $5 \% \mathrm{CO}_{2}$, cells were incubated in DMEM with $10 \%$ FBS (without gentamicin) for additional 2, 4, 8 or $24 \mathrm{~h}$. At these time points, cells were washed twice with D-PBS, lysed with $1 \%$ Saponin and survived bacteria were counted by plating.

\section{ROS Production}

Production of reactive oxygen species (ROS) by in vitro infected PAMs was measured using chemiluminescence (CL) assay (20). After overnight incubation of PAMs in 96 -well plates $\left(37^{\circ} \mathrm{C}, 5 \%\right.$ 
$\mathrm{CO}_{2}$ ), the wells were washed with Hanks' balanced salt solution (HBSS, Lonza) and luminol-derivative L-012 (Wako Chemicals $\mathrm{GmbH}$ ) was added to amplify the CL induced by respiratory burst of stimulated PAMs. L-012 was diluted in HBSS to the final concentration $0.15 \mathrm{mmol} / \mathrm{L}$. A suspension of G. parasuis (MOI 10) pre-incubated with/without the post-vaccinal IgG was then added to the wells containing luminol L-012. The same volume of HBSS was added to the non-infected PAMs that served as a control. Chemiluminescence was measured at $37^{\circ} \mathrm{C}$ using a multi-detection microplate reader Synergy H1 (BioTek) in kinetic mode for $1 \mathrm{~h}$. The results are expressed as integrals of chemiluminescence intensity (per $1 \times 10^{5}$ viable cells) induced in PAMs with infection, and data are presented as percentage relative to the non-infected control.

\section{Quantitative RT-PCR}

The total RNA was isolated from the infected and the non-infected PAMs at 4 and $24 \mathrm{~h}$ post infection (PI) by using RLT buffer (Qiagen) and an RNeasy Mini Kit (Qiagen) following manufacturer's instructions and then reverse transcribed with oligo-dT primer and M-MLV reverse transcriptase (Invitrogen). Primers for IL-1RN gene were designed using the freely available Basic Local Alignment Search Tool (http://www.ncbi.nlm.nih.gov/ blast/Blast.cgi). The remaining primers were designed according to the published papers and all are listed in Table 1. For real time PCR, LightCycler 480 II instrument (Roche) with a 384-well plate block was used. Each PCR reaction consisted of QuantiTect SYBR Green master mix (Qiagen), $1 \mu \mathrm{M}$ of each primer and $0.5 \mu \mathrm{L}$ of cDNA in a total volume of $3 \mu \mathrm{L}$. Briefly, PCR assay was performed under the following conditions: $95^{\circ} \mathrm{C}$ for $15 \mathrm{~min} ; 45 \mathrm{x} 95^{\circ} \mathrm{C}$ for $15 \mathrm{~s}, 58^{\circ} \mathrm{C}$ for $30 \mathrm{~s}, 72^{\circ} \mathrm{C}$ for $30 \mathrm{~s}$. Melting analysis was performed at $60-95^{\circ} \mathrm{C}$. Samples from each well were run in triplicate. Genes expression were calculated as multiples of the reference gene expression (Hypoxanthine phosphoribosyltransferase, HPRT) using the following formula: $\left(1 /\left(2^{\text {Ctgene }}\right)\right) /\left(1 /\left(2^{\mathrm{CtHPRT}}\right)\right)(24)$. The final value of the expression is shown as the ratio of gene expression in the infected sample to expression in the non-infected.

\section{Cytokine Assay}

Production of IL-1ß, TNF- $\alpha$, IL-8, IL-10 and IL-1Ra at a protein level was measured in the cell culture supernatants from PAMs infected with $G$. parasuis for 4 and 24 h by commercial ELISA kits ( $R \& D$ systems) according to the manufacturer's instructions.

\section{Statistical Analysis}

Data were analyzed using the Wilcoxon matched-pair singed rank test in GraphPad Prism (GraphPad Software, Inc.). A Pvalue less than 0.05 was considered significant. In graphs, data are expressed as means \pm SEM.

\section{RESULTS}

\section{The Capsule Detection}

Using the negative staining and transmission electron microscope, we observed the capsule in all G. parasuis strains (Figure 1).

\section{Antibodies Against the Crude Capsular Extract}

Immunization of pigs with the crude capsular extract led to humoral immune response that was confirmed by the in-house indirect ELISA. Whereas, the anti-cCE IgG antibodies were not detected before the immunization, after the second immunization with the $\mathrm{cCE}$ the anti-cCE IgG were observed in significantly high levels $(\mathrm{p}<0.0001)$ (Figure 2A).

The Western-blotting showed that the antibodies from the immunized animals reacted with proteins in the $\mathrm{CCE}$ of different molecular weights, which was not observed in case of the antibodies from the non-immunized pigs (Figure 2B). The strongest band on the membrane was in the area about 50 $\mathrm{kDa}$. Due to the preparation method of the $\mathrm{cCE}$, we expected protein content and thus we analyzed it by mass spectrometry. The crude capsular extract contained more than 100 bacterial proteins (Supplementary Material 1), like outer membrane proteins (Omp P5, Omp P2), virulence-associated autotransporters (VtaA) or cytolethal distending toxins (CDT). The most abundant protein found in the extract was Catalase (Uniprot accession number U4RLR7) with a molecular weight of $54.9 \mathrm{kDa}$.

To determine immunogenic proteins in the capsular extract, we performed the immunoprecipitation of the capsular extract with IgG isolated from positive or negative pooled serum and analyzed captured bacterial proteins by mass spectrometry. The most reactive proteins with positive serum previously described as virulence factors in $G$. parasuis were catalase, superoxide dismutase, Omp 26, CdtC, Plp4, Omp 5, and VtaA6 (Figure 3).

TABLE 1 | Primers used for the real-time PCR quantification of IL-1B, TNF- $\alpha$, IL-10, IL-1RN and HPRT.

\begin{tabular}{|c|c|c|}
\hline Target gene & Primers & Name/Function/Reference \\
\hline \multirow[t]{2}{*}{$\mathrm{IL}-1 ß$} & F: GGGACTTGAAGAGAGAAGTGG & Interleukin 1 beta \\
\hline & R: CTICCCTTGATCCCTAAGGT & Pro-inflammatory cytokine/ (21) \\
\hline \multirow[t]{2}{*}{$\mathrm{TNF}-\alpha$} & F: CCCCCAGAAGGAAGAGTTTC & Tumor necrosis factor \\
\hline & R: CGGGCTTATCTGAGGTTGA & Pro-inflammatory factor/ (22) \\
\hline \multirow[t]{2}{*}{$\mathrm{IL}-10$} & F: TGAAGAGTGCCTITAGCAAGCTC & Interleukin 10 \\
\hline & R: CTCATCTTCATCGTCATGTAGGC & Anti-inflammatory cytokine/ (23) \\
\hline \multirow[t]{2}{*}{ IL-1RN } & F: AGGGAAGCTGTGCCTGTCCTGTG & Interleukin-1 receptor antagonist \\
\hline & R: GGCCACTGTCGGAGCGGATGAAG & Antagonist of receptor for cytokine IL-1 beta/In this study \\
\hline \multirow[t]{2}{*}{ HPRT } & F: GAGCTACTGTAATGACCAGTCAACG & Hypoxanthine phosphoribosyltransferase \\
\hline & R: CCAGTGTCAATTATATCTTCAACAATCAA & Housekeeping gene/ (19) \\
\hline
\end{tabular}


A

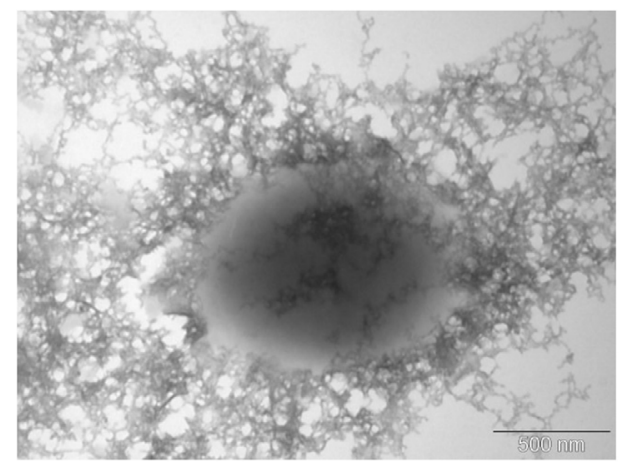

B

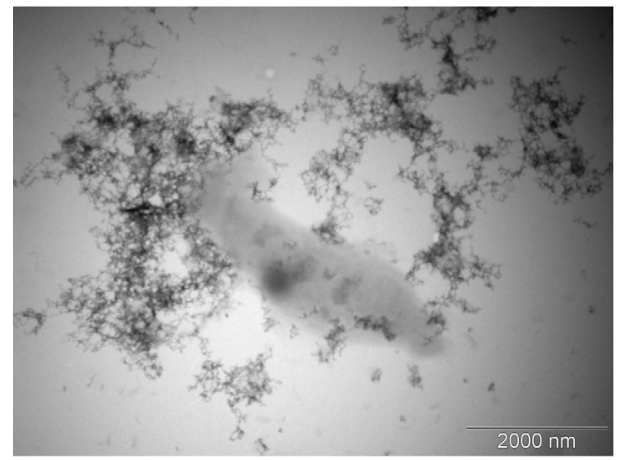

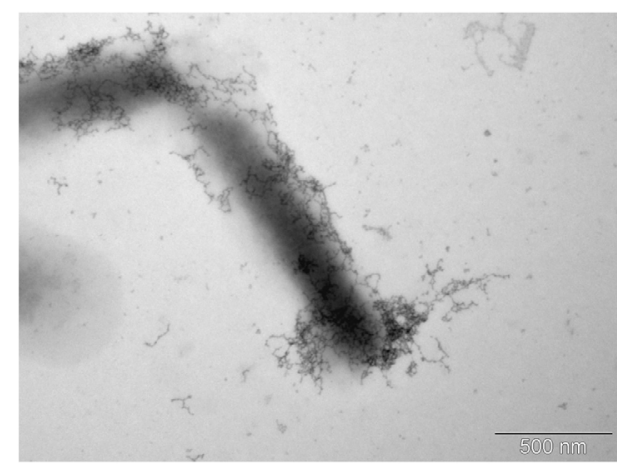

D

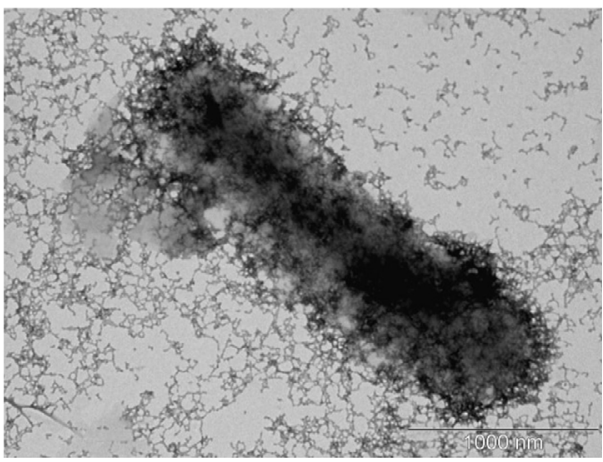

E

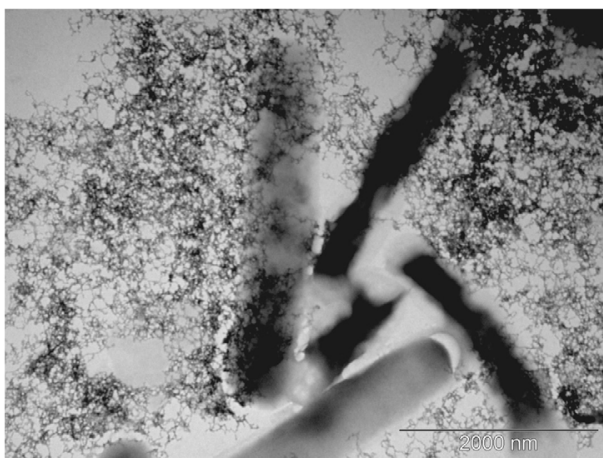

FIGURE 1 | Transmission electron microscopy of the capsule. Encapsulated G. parasuis avirulent strains (A, B) and virulent strains (C-E) are following: strain 131 of serovar 6 (A), strain D74 of serovar 9 (B), strain No.4 of serovar 1 (C), strain CAPM 6475 of serovar 5 (D), and strain H425 of s. 12 (E).

To confirm and visualize binding of the post-vaccinal antibodies with G. parasuis, we performed the transmission electron microscopy of G. parasuis strain CAPM 6475 incubated with positive or negative sera using the protein A conjugated with $20 \mathrm{~nm}$ colloidal gold. As we expected, we observed bacteria with bound antibodies visualized with gold particles only in a case of incubation with positive pooled serum (Figure 4).

\section{Phagocytosis Assay and Survival Assay After Phagocytosis}

Survival of each G. parasuis strain inside PAMs $1 \mathrm{~h}$ after phagocytosis is shown in Figure 5A. Bacteria of serovar 9, 5 and 12 pre-incubated with the post-vaccinal IgG were present inside PAMs in significantly higher amounts than bacteria pre-incubated without the antibodies. On the other hand, opsonization of serovar 1 and 6 had no effect on their phagocytosis. To see kinetics of internalization process of bacteria, we performed phagocytosis assay in different time points. We chose bacterial strains (i.e. of serovar 9, 5, and 12) with a significantly higher number of ingested bacteria after opsonization compared to non-opsonized, which was observed after one hour of phagocytosis. This experiment revealed that opsonization of bacteria led to obviously higher uptake of bacteria up to $2 \mathrm{~h}$ of phagocytosis (Figures 5B-D). At $5 \mathrm{~h} \mathrm{PI}$, there was no difference in phagocytosis of the opsonized and non-opsonized bacteria.

In addition, to find out whether internalized bacteria survive inside PAMs, we determined number of viable bacteria in different time points after their internalization. Results of this experiment revealed that survival of ingested bacteria was not influenced by presence of IgG. Number of internalized bacteria of serovar 9 pre-incubated with IgG and without IgG was 

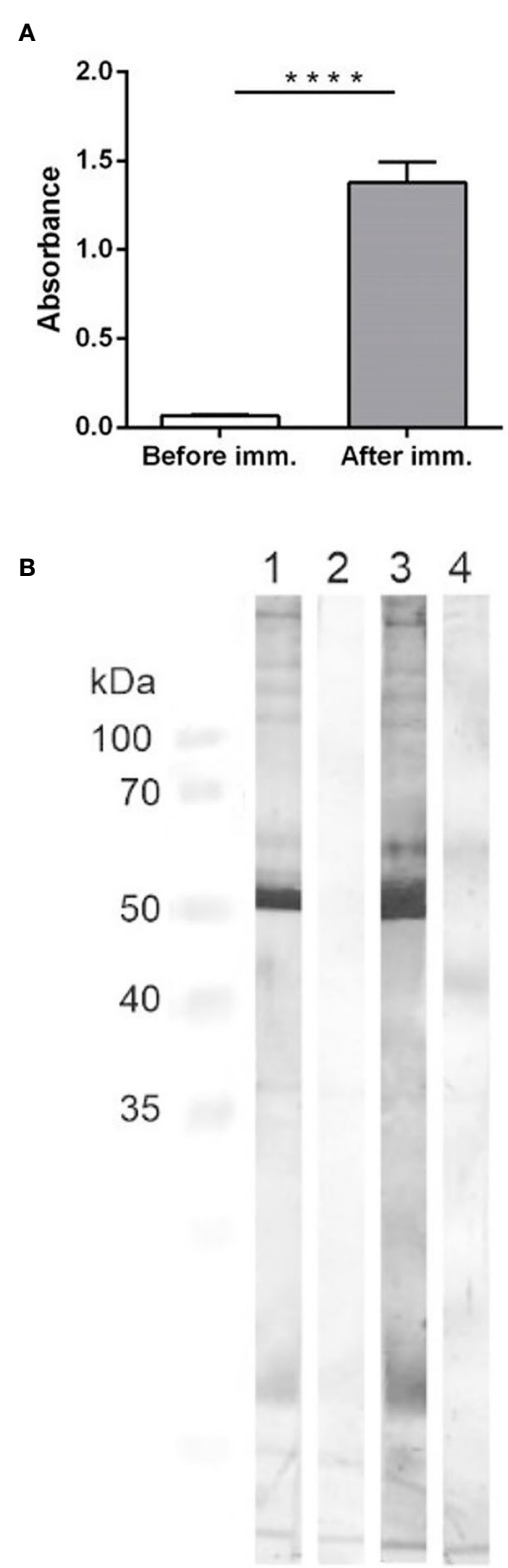

FIGURE 2 | (A): ELISA detection of specific antibodies against the crude capsular extract. The graph shows the antibody titer of antibodies in sera from pigs before the immunization and at 14 days after the second immunization with the cCE. Significant difference between the groups is denoted by asterisks $(p<0.0001)$. (B): Western-blotting. Antigen - the crude capsular extract. Primary antibodies: 1- IgG isolated from the positive pooled serum, 2 - IgG isolated from the negative pooled serum, 3 - positive pooled serum from pigs after the second immunization, 4 - negative pooled serum from pigs before the immunization. Secondary antibodies: goat anti-pig HRPconjugated IgG. Specific protein bands were visualized with 3, 3'diaminobenzidine.

reduced to $69.05 \%$ and $33.33 \%$ in $2 \mathrm{~h}$, to $11.59 \%$ and $1.67 \%$ in $4 \mathrm{~h}$ and to $0.28 \%$ and $0.00 \%$ in $8 \mathrm{~h}$, respectively. Number of internalized bacteria of serovar 12 pre-incubated with IgG and without IgG was reduced to $63.19 \%$ and $56.08 \%$ in 2 h, to $28.87 \%$ and $22.85 \%$ in $4 \mathrm{~h}$ and to $4.60 \%$ and $12.58 \%$ in $8 \mathrm{~h}$, respectively. Bacteria of both serovars were killed in $24 \mathrm{~h}$. In addition, bacteria of serovar 5 were killed in $2 \mathrm{~h}$ after phagocytosis.

\section{ROS Production}

Respiratory burst was measured using chemiluminescence assay in this study. Results of ROS production by PAMs during one hour of infection are expressed as integrals of the chemiluminescence signal and are shown in the Figure 6. All G. parasuis strains (except for serovar 12) without post-vaccinal IgG reduced ROS production below the level of spontaneous ROS production in the non-infected cells. On the other hand, opsonization of every $G$. parasuis strain with the post-vaccinal antibodies led to higher intensity of the CL signal in the infected PAMs comparing to PAMs affected with the non-opsonized bacteria.

\section{The Immune Response of PAMs to In Vitro Infection}

Results of mRNA expression of IL-1 $\beta$, IL- 8 , TNF- $\alpha$, IL-10 and IL-1RN gene at 4 and $24 \mathrm{~h}$ PI are shown in Figure 7. Higher mRNA expression of pro-inflammatory TNF- $\alpha$ and antiinflammatory IL-1RN gene was detected in PAMs infected with every $G$. parasuis strain pre-incubated with post-vaccinal IgG than without IgG at $4 \mathrm{~h}$ PI and $24 \mathrm{~h}$ PI, respectively. This phenomenon was observed also in case of IL- 8 when PAMs were infected for $4 \mathrm{~h}$ or $24 \mathrm{~h}$ with opsonized bacterial strains, except for serovar 5. Expression of IL-1 $\beta$ was higher in PAMs affected with virulent serovars for $4 \mathrm{~h}$ and with serovar 5 or 12 also for $24 \mathrm{~h}$ in the presence of IgG than without IgG. IL-10 was upregulated in PAMs incubated with serovar 12 for $4 \mathrm{~h}$ and with serovar 5 for $24 \mathrm{~h}$ in the presence of IgG.

IL-8, IL-10 and IL-RN genes were detected up-regulated more at $24 \mathrm{~h}$ PI than at $4 \mathrm{~h}$ PI in all groups at the transcriptional level. On the contrary, levels of mRNA expression of TNF- $\alpha$ gene were detected at $4 \mathrm{~h}$ PI above the levels at $24 \mathrm{~h}$ PI in all groups.

The ratio of mRNA expressions of IL- $1 \beta$ gene as the proinflammatory cytokine and IL-1RN gene (the interleukin1receptor antagonist) as the anti-inflammatory cytokine is illustrated in the Figure 8. At $24 \mathrm{~h}$ this ratio is lower for every bacterial strain in the presence of IgG, which infers that the IgG antibodies elevated mRNA expression of anti-inflammatory IL-1RN gene at this post-infection time. At $4 \mathrm{~h} \mathrm{PI}$, there is no difference in the opsonized and non-opsonized bacteria, except for serovar 12.

Concentrations of the selected cytokines at the protein level in the cell culture supernatants are shown in the Figure 9. Concentrations of IL-1RN gene product (i.e.IL-1Ra protein) and IL-10 were under the detectable levels of the used ELISA kits (data not shown). Production of IL- $1 \beta$ was lower after $4 \mathrm{~h}$ of infection than after $24 \mathrm{~h}$ and was significantly higher in PAMs infected with serovar 9 or 5 in the presence of IgG than without IgG at $24 \mathrm{~h} \mathrm{PI}$. Cells affected with serovar 1 or 6 for $4 \mathrm{~h}$ and with serovar 5 for $24 \mathrm{~h}$ produced significantly higher amount of IL- 8 in the presence of IgG than without them. TNF- $\alpha$ was produced in much higher concentrations by PAMs affected with every strain that was pre-incubated with the IgG than without antibodies at both PI times. 


\section{Protein PSM after immunoprecipitation}

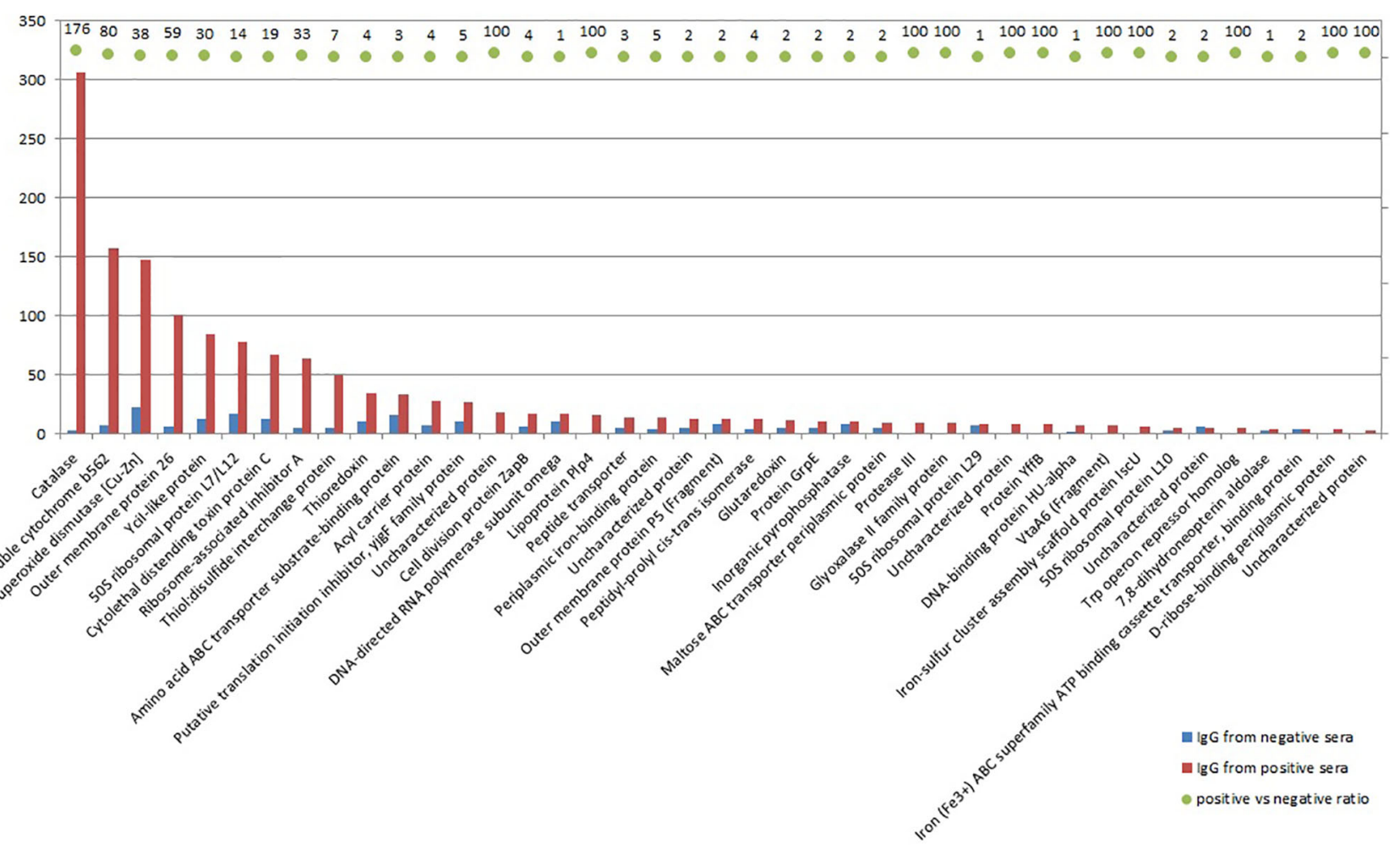

FIGURE 3 | Mass spectrometry analysis of bacterial proteins from the crude capsular extract precipitated with lgG antibodies isolated from positive or negative pooled serum. Bars in the graph show identified protein quantity by PSM (peptide spectrum match), whereas the ratio between positive and negative sera is expressed by AUC (area under the curve) for each corresponding protein. The ratio which equals 100 is maximum defined value meaning that the protein is not detected in negative sera at all.

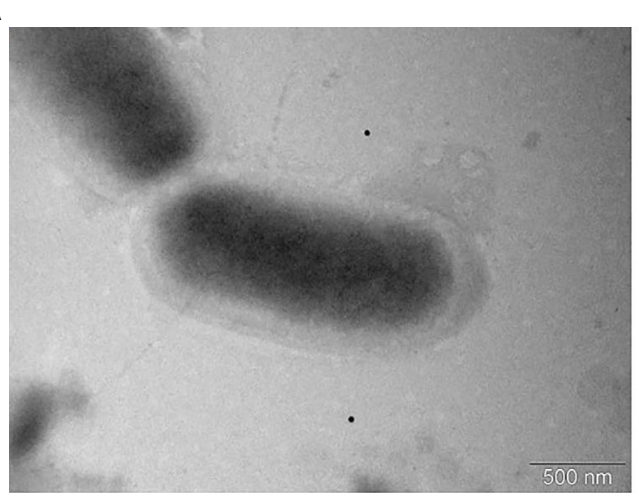

B

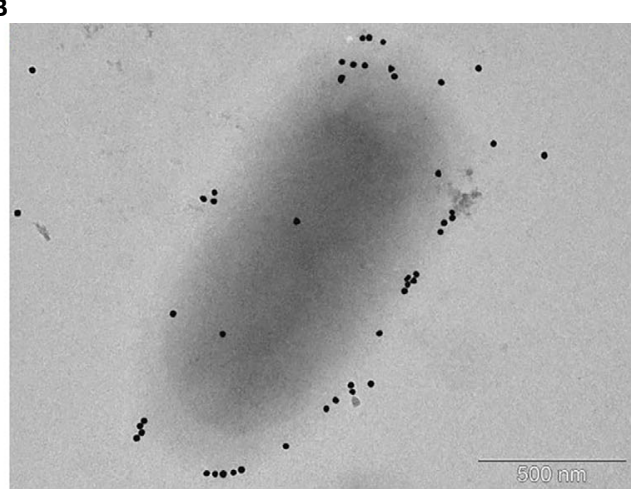

FIGURE 4 | Immunoelectron microscopy of G. parasuis strain CAPM 6475 incubated with pooled sera obtained from pigs before the immunization (A) or after the second immunization with the CCE (B). Serum antibodies bound to bacteria are indicated by gold particles (black spots) bound to Protein A.

\section{DISCUSSION}

G. parasuis is a commensal organism of the upper respiratory tract of pigs but it is also able to overcome the host innate immune system in the lungs (e.g. the alveolar macrophages) and cause systemic disease. The capsule is one of the virulence factors of this bacterium (4) and likely helps the bacterium to resist phagocytosis by alveolar macrophages (7). In our study, 
A

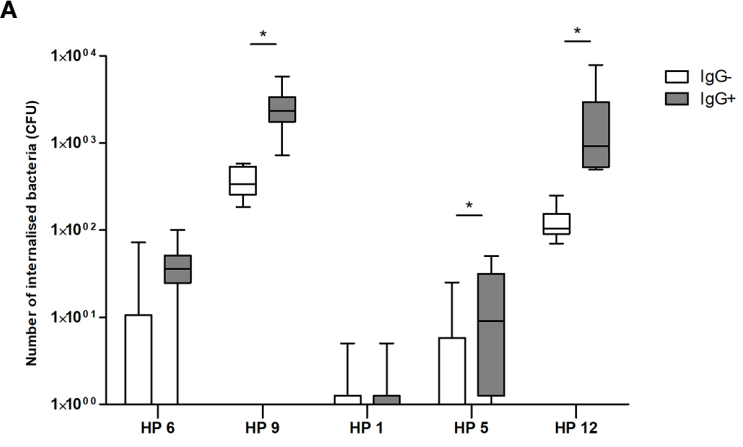

C
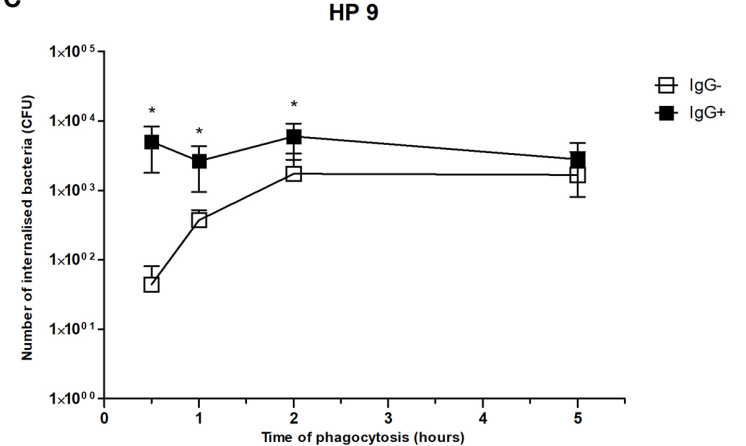

B

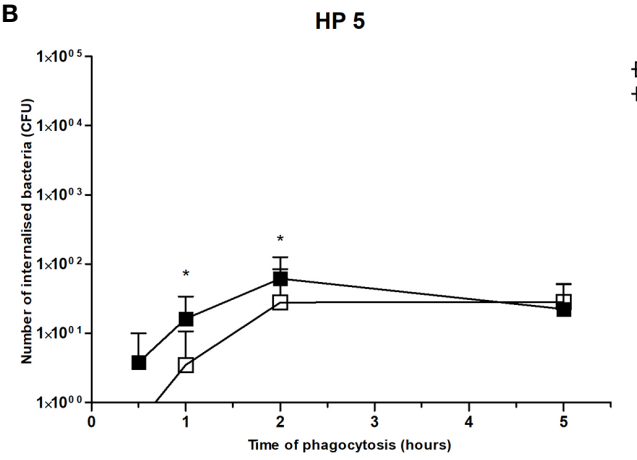

D

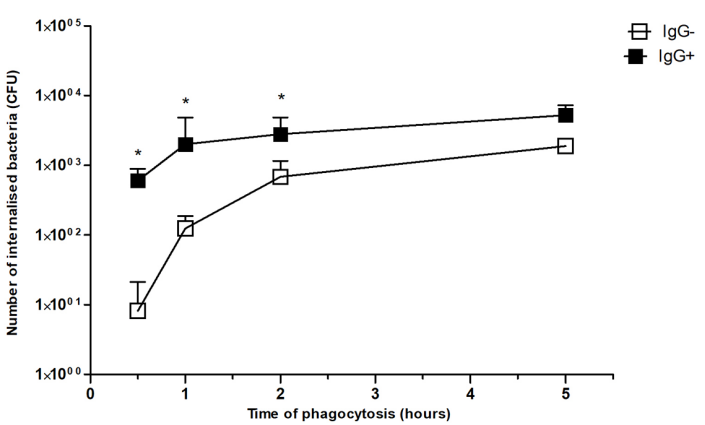

FIGURE 5 | Phagocytosis assay. Data show presence of G. parasuis strains pre-incubated with (lgG+) or without (IgG-) the post-vaccinal lgG in lysed PAMs after one hour of phagocytosis (A) or after 0.5, 1, 2 and $5 \mathrm{~h}$ of phagocytosis (B-D). Significant difference between groups with or without the post-vaccinal lgG is denoted by asterisk $(p<0.05)$.

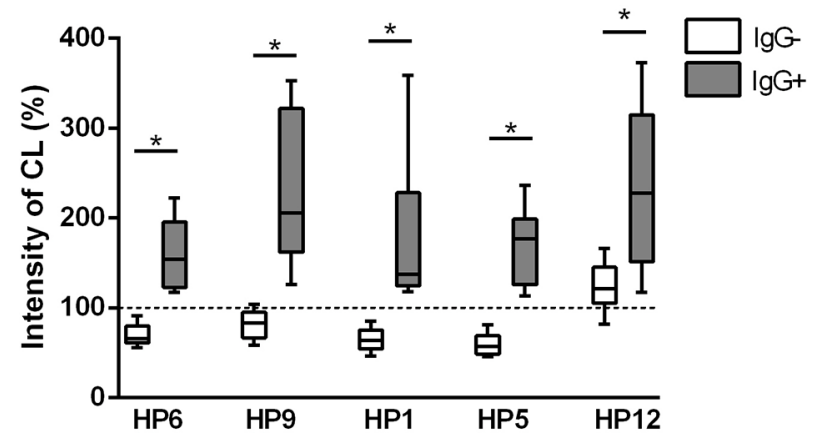

FIGURE 6 | ROS production. ROS production was measured for $1 \mathrm{~h}$ by chemiluminescence assay in PAMs infected with various strains of $G$. parasuis pre-incubated with (lgG+) or without the post-vaccinal $\operatorname{lgG}(\operatorname{lgG}-)$. Data are presented as percentage of integral of the chemiluminescence signal levels compared to the non-infected PAMs. Significant difference between groups with or without the $\lg G$ is denoted by asterisk $(p<0.05)$.

PAMs were able to recognize and phagocyte G. parasuis with strain-to-strain variability despite presence of the capsule observed in the virulent as well as in the avirulent strains. Differences in phagocytosis and in presence of the capsule of G. parasuis strains between our study and studies of other authors may be caused by different capsule structure, various gene expression in the main capsule loci under diverse conditions of growth or host environment, phagocytosis resistance mechanism or by other virulence factors (7-10, 24, 25). To determine whether IgG antibodies against the crude capsular extract of the virulent $G$. parasuis strain CAPM4675 increase phagocytosis of various $G$. parasuis strains in vitro, we isolated IgG from sera of the cCE-immunized pigs, incubated different $G$. parasuis strains with these IgG and subsequently infected PAMs. We used these antibodies because mice immunized with the $\mathrm{CCE}$ in our previous study were partially protected against the challenge with various $G$. parasuis strains and the anti-cCE antibodies in mice sera were able to bind to various strains in the Western-blotting (13). In addition, we proved the specific reactivity of the post-vaccinal antibodies from positive pig sera with the capsular extract as well as with various $G$. parasuis strains also by the Western-blotting, TEM and immunoprecipitation method.

We found that opsonization of bacteria by the post-vaccinal IgG led to enhanced phagocytosis of avirulent serovar 9 and virulent serovar 5 and 12 in the first two hours of infection. After $5 \mathrm{~h}$ of infection, previous opsonization had no effect on uptake of bacteria by macrophages. Moreover, opsonization of bacteria had no effect on their survival inside PAMs. Internalized bacteria were killed in $24 \mathrm{~h}$ after their phagocytosis. 


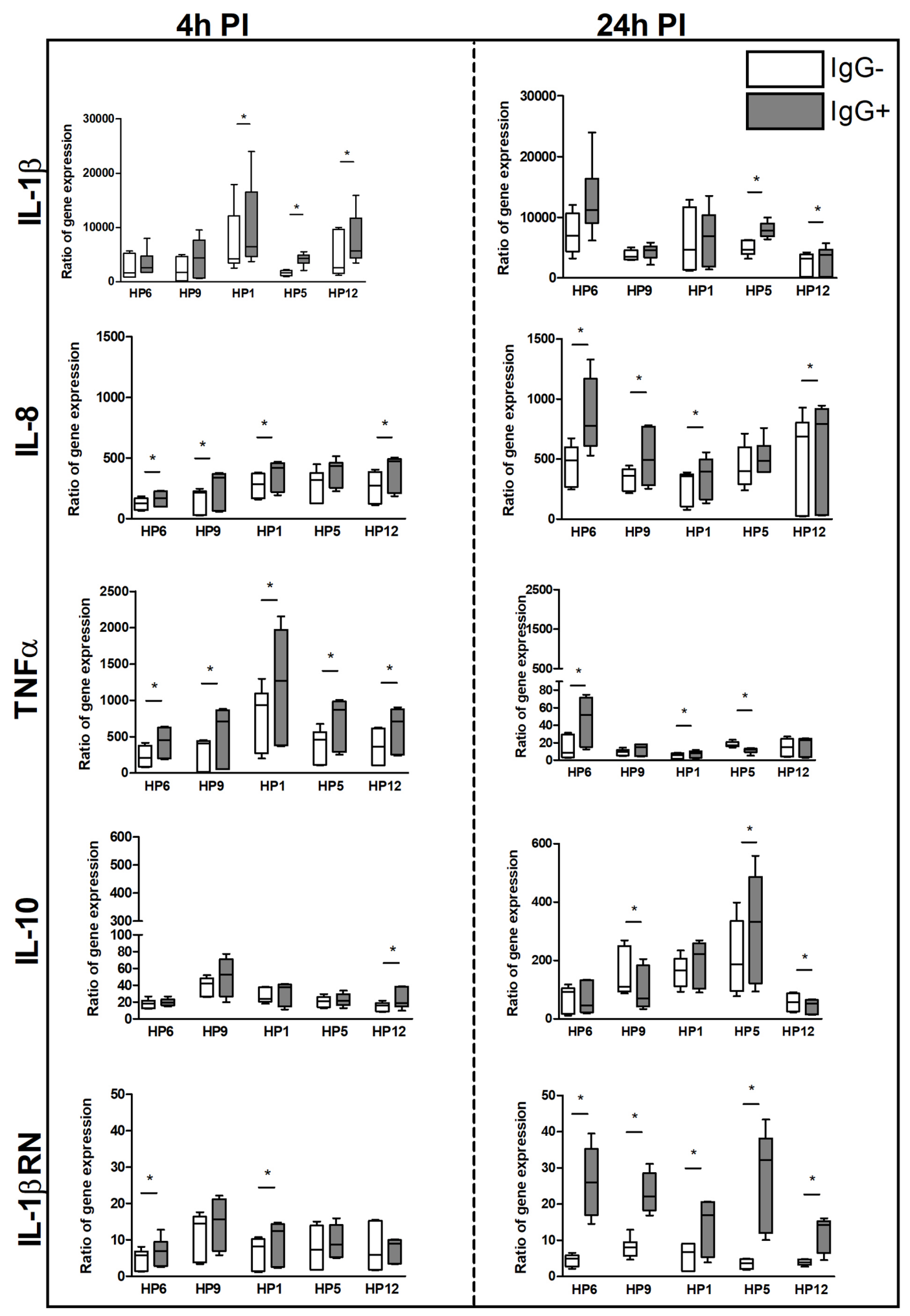

FIGURE 7 | The immune response of PAMs at the transcriptional level. PAMs were infected with various G. parasuis strains for 4 and $24 \mathrm{~h}$. The mRNA expression of IL-1 $\beta, I L-8, T N F-\alpha, I L-10$ and IL-1RN was measured by real-time PCR at these PI times. The degree of gene expression was calculated as a fold of the reference gene expression, hypoxanthine phosphoribosyltransferase, and final results are displayed as the ratio of gene expression in the infected sample to expression in the non-infected. Significant difference between groups with (lgG+) or without (lgG-) the post-vaccinal lgG is denoted by asterisk ( $p<0.05)$. 


\section{IL-1 $\beta / I L R N ~ 4 h$}

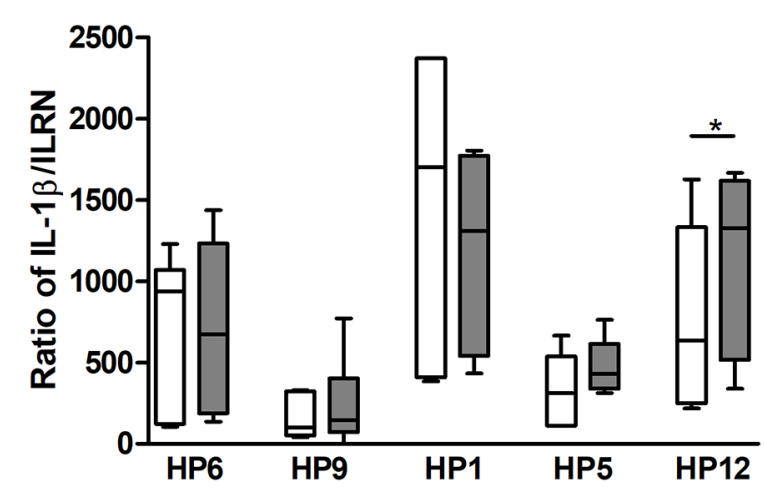

IL-1ß/ILRN 24h

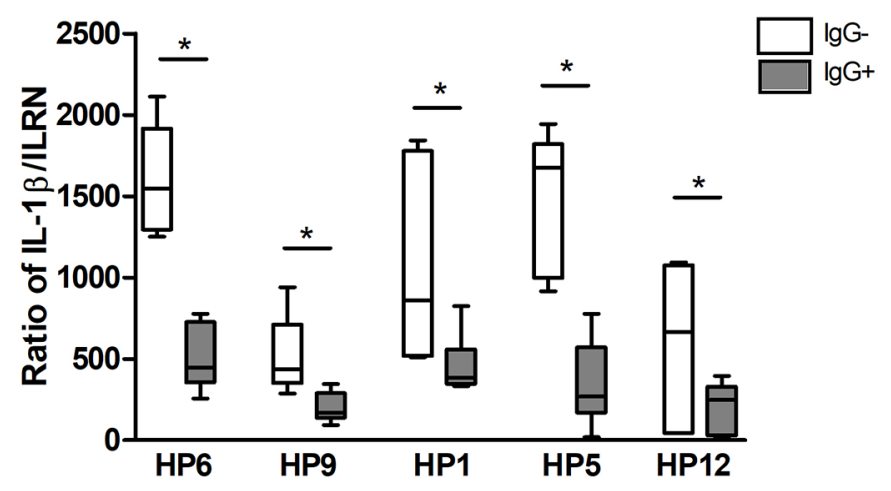

FIGURE 8 | The ratio of mRNA expressions of IL-1 $\beta$ (pro-inflammatory cytokine) and IL-1Ra (the interleukin1-receptor antagonist, anti-inflammatory cytokine) at 4 and $24 \mathrm{~h} \mathrm{PI}$. Significant difference between groups with (lgG+) or without (lgG-) the post-vaccinal lgG is denoted by asterisk ( $\mathrm{p}<0.05)$.

Using mass spectrometry, we found some virulenceassociated proteins in the capsular extract that reacted with the post-vaccinal IgG antibodies and thus may be also responsible for enhanced phagocytosis of G. parasuis. For example, we detected the virulence-associated trimeric autotransporters (VtaA) VtaA6 that reacted with positive pig sera and not with negative sera. An IgG antibody response against VtaA6 (beside VtaA1, 5, 8, 9 and 10) was also detected in sera of pigs after experimental challenge with G. parasuis Nagasaki strain but not after immunization with G. parasuis Nagasaki bacterin (26). Authors indicated only in vivo expression of these proteins. However, we were able to isolate the $\mathrm{CCE}$ with $\mathrm{VtaA}$ in vitro, likely because of the preparation method, and this extract was able to enhance antibody response in pigs. Two other virulenceassociated trimeric autotransporters, VtaA8 and VtaA9, were revealed as surface proteins of virulent strain PC4-6P (serovar 12) that delayed phagocytosis of this strain by PAMs. In addition, when this strain was opsonized with monoclonal antibodies against these two VtaA its phagocytosis was enhanced (9). Although we did not detect these VtaA amongst the precipitated proteins, we observed the same phenomenon of delayed phagocytosis in serovar 5, 9 and 12 in comparison to the non-opsonized bacteria. Thus, we speculate that the postvaccinal IgG antibodies promoted phagocytosis of these strains by binding to their VtaA6 or other VtaA detected in the cCE. On the other hand, the VtaA 8 and 9 were not detected in an avirulent strain F9 of serovar 6 that was properly internalized and degraded in acidic compartments of an early endosome (9). Therefore, the absence of $\mathrm{VtaA}$ in serovar 6 and 1 may be an explanation of no elevation in phagocytosis after their opsonization with the post-vaccinal antibodies in our study. Of course, other mechanisms or virulence factors may be involved in phagocytosis resistance.

Catalase and superoxide dismutase (SOD) were other detected virulence-associated proteins that precipitated with the postvaccinal antibodies. These proteins are the antioxidants that bacteria use to neutralize destructive effects of reactive oxygen species (e.g., superoxide anion, hydrogen peroxide, singlet oxygen, hydroxyl radicals) produced during the oxidative burst (27). The luminol-amplified chemiluminescence is able to detect superoxide anion as well as hydrogen peroxide in the presence of peroxidases (28). Because decomposition of these reactive oxygen species is catalyzed by the superoxide dismutase and catalase, these two enzymes apparently play an important role in the oxidative stress resistance of G. parasuis observed in our study as well as by other authors $(20,29,30)$. Moreover, catalase was identified among the secreted proteins of G. parasuis Nagasaki strain as immunoreactive with G. parasuis anti-Nagasaki convalescent sera (31). In our study, all G. parasuis strains opsonized with the post-vaccinal $\operatorname{IgG}$ significantly increased the CL signal in PAMs suggesting the inhibiting effect of these antibodies on the antioxidant mechanism of the bacteria. Neutralization of the antioxidant mechanisms of $G$. parasuis may lead to attenuation of this bacterium with subsequent lower ability to induce disease. Additionally, protective effect of antibodies against superoxide dismutase was observed in mice after G. parasuis lethal challenge (32). When we compared the translated amino acid sequences from whole-genome sequencing from the publication of Brockmeier et al. (33), protein sequences of catalase and SOD are very similar among serovars - approx. 99\% identity among tested serovars for catalase and $94 \%$ for superoxide dismutase (data not shown). We may thus expect the crossreactivity of the anti-cCE antibodies at some reasonable level.

In macrophages, ROS also mediate signal transduction through oxidation of susceptible cysteine residues present in a number of proteins that regulate NF- $\mathrm{KB}$ activation (34). G. parasuis activates $\mathrm{p} 38$ and the c-Jun amino-terminal kinase (JNK) that along with NF- $\mathrm{KB}$ activation lead to up-regulation of pro-inflammatory cytokines and chemokines in host cells (35$37)$. Our results of higher mRNA expression of proinflammatory TNF- $\alpha$ gene at $4 \mathrm{~h}$ PI and IL- $1 \beta$ gene at both PI times indicate the stronger early immune response of macrophages in the presence of the post-vaccinal IgG opsonizing G. parasuis. Based on the results of ratio IL-1 $\beta$ and IL-1RN gene expression, the early immune response may be substituted in presence of the post-vaccinal antibodies by higher expression of antagonist for IL- $1 \beta$ receptor at $24 \mathrm{~h}$ PI that may 


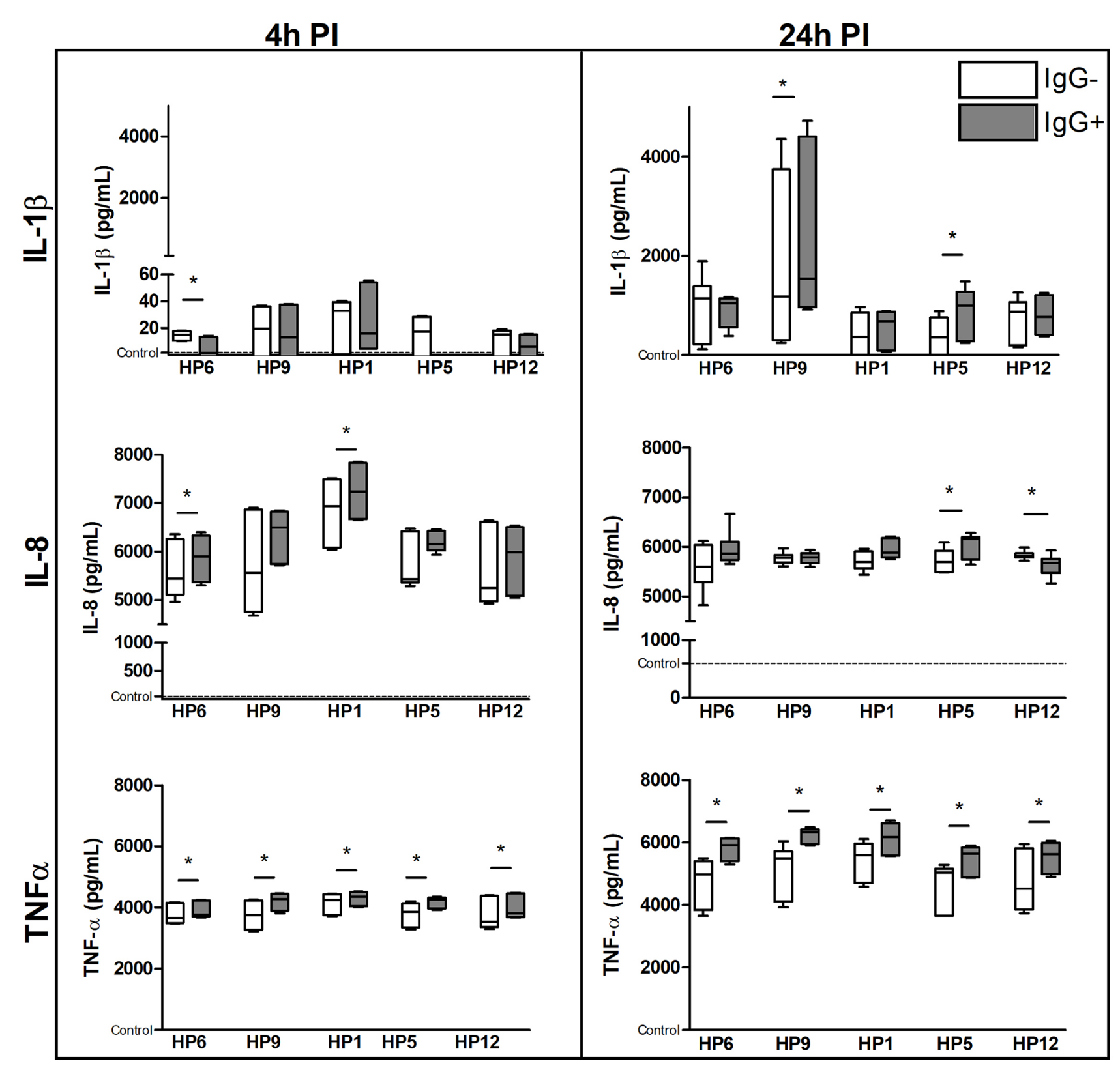

FIGURE 9 | The immune response of PAMs at a protein level. PAMs were infected with various G. parasuis strains for 4 and $24 \mathrm{~h}$. The concentration of IL-1 13 , IL-8 and TNF- $\alpha$ was measured by commercial ELISA kits at these PI times. Significant difference between groups with (IgG+) or without (IgG-) the post-vaccinal lgG is denoted by asterisk $(p<0.05)$. Dotted line displays expression of mRNA in the control non-infected cells.

inhibit the negative effects of produced pro-inflammatory IL-1 $\beta$ to the surrounding tissues in host. The kinetics of their activation confirms the fact that IL-1Ra (i.e. IL-1RN gene product) is an important negative feedback regulator of $\operatorname{IL}-1 \beta(38,39)$. Additionally, these two cytokines may be influenced by another cytokine such as the anti-inflammatory cytokine IL-10 that down-regulates the expression of IL-1 $\beta$ and up-regulates the expression of IL-1RN genes (40). Higher expression of IL-10 gene detected in the infected PAMs at $24 \mathrm{~h}$ PI may be due to the potent effect of IL-1 $\beta$ and TNF- $\alpha$ produced in higher levels at this PI time $(41,42)$. Moreover, IL-10 inhibits the activity of TNF- $\alpha$ (43) that maybe a reason of TNF- $\alpha$ down-regulation observed at mRNA level at $24 \mathrm{~h}$ PI. TNF- $\alpha$ and IL-10 may play a role in the adaptive response of host organism to $G$. parasuis infection (44). Higher production of TNF- $\alpha$ by PAMs infected with $G$. parasuis pre-incubated with the post-vaccinal IgG than without the antibodies may indicate a role of this cytokine in a humoral response $(44,45)$. TNF- $\alpha$ is able to induce IL- 8 production (43). IL-8 is a chemokine that attracts neutrophils to the inflammation site with their subsequent activation and 
ROS production leading to enhanced killing of pathogens (46). The mRNA expression of IL-8 gene was even higher in the presence of the post-vaccinal IgG than without IgG. Higher production of pro-inflammatory cytokines in the presence of IgG antibodies confirm the pro-inflammatory response following Fcmediated phagocytosis $(47,48)$.

To summarize, opsonization of $G$. parasuis by antibodies against the crude capsular extract of strain CAPM 6475 enhanced phagocytosis of various strains independent of virulence. Different susceptibility of encapsulated G. parasuis strains to phagocytosis observed in our study could be due to different structure of the capsule, diverse gene expression for capsule production, or presence of various virulence factors like the VtaA. Moreover, opsonization of bacteria promoted phagocytosis up to $2 \mathrm{~h}$ PI which indicate the role of antibodies in the first hours of infection. Although $G$. parasuis infection of PAMs led to inhibition of ROS production (likely of superoxide anion and hydrogen peroxide), opsonization by the post-vaccinal IgG increased the oxidative burst. Because catalase and SOD were detected in the capsular extract and reacted with sera of the cCEimmunized pigs, we presume that these antibodies had neutralizing effects on catalase and SOD of G. parasuis in PAMs infection. Together with higher expression/production of pro- and anti-inflammatory cytokines, antibodies against the cCE may lead to attenuation of this bacterium with subsequent lower ability to induce disease at early stage of infection. Taken together, the crude capsular extract is a promising vaccine candidate. Therefore, our next step is to perform an experimental challenge of pigs with different G. parasuis strains after their immunization with the $\mathrm{CCE}$ vaccine.

\section{DATA AVAILABILITY STATEMENT}

The datasets presented in this study can be found in online repositories. The names of the repository/repositories and accession number(s) can be found in the article/ Supplementary Material.

\section{REFERENCES}

1. Dickerman A, Bandara AB, Inzana TJ. Phylogenomic Analysis of Haemophilus Parasuis and Proposed Reclassification to Glaesserella Parasuis, Gen. Nov., Comb. Nov. Int J Syst Evol Microbiol (2019) 70:180-6. doi: 10.1099/ijsem.0.003730

2. Amano H, Shibata M, Kajio N, Morozumi T. Pathologic Observations of Pigs Intranasally Inoculated With Serovar 1, 4 and 5 of Haemophilus Parasuis Using Immunoperoxidase Method. J Vet Sci (1994) 56:639-44. doi: 10.1292/ jvms.56.639

3. Kielstein P, Rapp-Gabrielson VJ. Designation of 15 Serovars of Haemophilus Parasuis on the Basis of Immunodiffusion Using Heat-Stable Antigen Extractst. J Clin Microbiol (1992) 30:862-5. doi: 10.1128/JCM.30.4.862865.1992

4. Zhang B, Tang C, Liao M, Yue H. Update on the Pathogenesis of Haemophilus Parasuis Infection and Virulence Factors. Vet Microbiol (2014) 168:1-7. doi: 10.1016/j.vetmic.2013.07.027

\section{ETHICS STATEMENT}

The animal study was reviewed and approved by the Branch Commission for Animal Welfare of the Ministry of Agriculture of the Czech Republic (approval protocols No. MZe 1704 and MZe 1487).

\section{AUTHOR CONTRIBUTIONS}

KM and MF designed the study. KM prepared the crude capsular polysaccharide extract. $\mathrm{KN}$ immunized pigs. JG performed the mass spectrometry analysis and immunoprecipitation. PK performed the TEM and immunoelectron microscopy. RT performed the Western-blotting analysis. HK performed the ELISA test. KM and LK performed in vitro experiments. KM analyzed data, performed statistical analysis and wrote the manuscript. All authors contributed to the article and approved the submitted version.

\section{FUNDING}

The study was supported by the project IGA VFU Brno 123/ 2017/FVL of the University of Veterinary and Pharmaceutical Sciences, the projects of the Ministry of Education, Youth and Sports of the Czech Republic (CZ.02.1.01/0.0/0.0/15_003/ 0000495 and CZ.1.05/2.1.00/19.0385) and the project RO 0518 of the Ministry of Agriculture of the Czech Republic.

\section{SUPPLEMENTARY MATERIAL}

The Supplementary Material for this article can be found online at: https://www.frontiersin.org/articles/10.3389/fimmu.2021. 635097/full\#supplementary-material

Supplementary Material 1 | Proteins identified by mass spectrometry analysis of the crude capsular extract.

5. Sibille Y, Reynolds HY. Macrophages and Polymorphonuclear Neutrophils in Lung Defense and Injury. Am Rev Respir Dis (1990) 141:471-501. doi: 10.1164/ajrccm/141.2.471

6. Rosenberger CM, Finlay BB. Phagocyte Sabotage: Disruption of Macrophage Signalling by Bacterial Pathogens. Nat Rev Mol Cell Biol (2003) 4:385-96. doi: 10.1038/nrm1104

7. Olvera A, Ballester M, Nofrarias M, Sibila M, Aragon V. Differences in Phagocytosis Susceptibility in Haemophilus Parasuis Strains. Vet Res (2009) 40:24. doi: 10.1051/vetres/2009007

8. Perry MB, MacLean LL, Gottschalk M, Aragon V, Vinogradov E. Structure of the Capsular Polysaccharides and Lipopolysaccharides From Haemophilus Parasuis Strains ER-6P (Serovar 15) and Nagasaki (Serovar 5). Carbohydr Res (2013) 378:91-7. doi: 10.1016/j.carres.2013.04.023

9. Costa-Hurtado M, Ballester M, Galofré-Milà N, Darji A, Aragon V. VtaA8 and VtaA9 From Haemophilus Parasuis Delay Phagocytosis by Alveolar Macrophages. Vet Res (2012) 43:57. doi: 10.1186/12979716-43-57 
10. Barasuol BM, Guizzo JA, Fegan JE, Martínez-Martínez S, Rodríguez-Ferri EF, Gutiérrez-Martín CB, et al. New Insights About Functional and CrossReactive Properties of Antibodies Generated Against Recombinant TbpBs of Haemophilus Parasuis. Sci Rep (2017) 7:10377. doi: 10.1038/s41598-01710627-0

11. Cerdà-Cuéllar M, Aragon V. Serum-Resistance in Haemophilus Parasuis is Associated With Systemic Disease in Swine. Vet J (2008) 175:384-9. doi: 10.1016/j.tvjl.2007.01.016

12. Celli J, Finlay BB. Bacterial Avoidance of Phagocytosis. Trends Microbiol (2002) 10:232-7. doi: 10.1016/S0966-842X(02)02343-0

13. Matiaskova K, Nedbalcova K, Tesarik R, Kudlackova H, Gebauer J, Toman M, et al. A Crude Capsular Polysaccharide Extract as a Potential Novel Subunit Vaccine With Cross-Protection Against the Most Prevalent Serovars of Glaesserella (Haemophilus) Parasuis in the Czech Republic. Vet Med (Praha) (2019) 64:392-9. doi: 10.17221/71/ 2019-VETMED

14. Nedbalcova K, Kucerova Z, Krejci J, Tesarik R, Gopfert E, Kummer V, et al. Passive Immunization of Post-Weaned Piglets Using Hyperimmune Serum Against Experimental Haemophilus Parasuis Infection. Res Vet Sci (2011) 91:225-9. doi: 10.1016/j.rvsc.2010.12.008

15. Macedo N, Rovira A, Torremorell M. Haemophilus Parasuis: Infection, Immunity and Enrofloxacin. Vet Res (2015) 46:128. doi: 10.1186/s13567-015-0263-3

16. Liu H, Xue Q, Zeng Q, Zhao Z. Haemophilus Parasuis Vaccines. Vet Immunol Immunopathol (2016) 180:53-8. doi: 10.1016/j.vetimm.2016.09.002

17. Huebner J, Wang Y, Krueger WA, Madoff LC, Martirosian G, Boisot S, et al. Isolation and Chemical Characterization of a Capsular Polysaccharide Antigen Shared by Clinical Isolates of Enterococcus Faecalis and Vancomycin-Resistant Enterococcus Faecium. Infect Immun (1999) 67:1213-9. doi: 10.1128/IAI.67.3.1213-1219.1999

18. Wiśniewski JR, Zougman A, Nagaraj N, Mann M. Universal Sample Preparation Method for Proteome Analysis. Nat Methods (2009) 6:359-62. doi: $10.1038 /$ nmeth.1322

19. Zelnickova P, Matiasovic J, Pavlova B, Kudlackova H, Kovaru F, Faldyna M. Quantitative Nitric Oxide Production by Rat, Bovine and Porcine Macrophages. Nitric Oxide (2008) 19:36-41. doi: 10.1016/j.niox. 2008.04.001

20. Kavanová L, Matiašková K, Levá L, Štěpánová $\mathrm{H}, \mathrm{Nedbalcová} \mathrm{K,} \mathrm{Matiašovic} \mathrm{J,}$ et al. Concurrent Infection With Porcine Reproductive and Respiratory Syndrome Virus and Haemophilus Parasuis in Two Types of Porcine Macrophages: Apoptosis, Production of ROS and Formation of Multinucleated Giant Cells. Vet Res (2017) 48:28. doi: 10.1186/s13567-0170433-6

21. Pavlova B, Volf J, Ondrackova P, Matiasovic J, Stepanova H, Crhanova M, et al. SPI-1-Encoded Type III Secretion System of Salmonella Enterica is Required for the Suppression of Porcine Alveolar Macrophage Cytokine Expression. Vet Res (2011) 42:16. doi: 10.1186/1297-9716-42-16

22. Volf J, Boyen F, Faldyna M, Pavlova B, Navratilova J, Rychlik I. Cytokine Response of Porcine Cell Lines to Salmonella Enterica Serovar Typhimurium and Its Hila and Ssra Mutants. Zoonoses Public Health (2007) 54:286-93. doi: $10.1111 / j .1863-2378.2007 .01064 . x$

23. Kyrova K, Stepanova H, Rychlik I, Faldyna M, Volf J. SPI-1 Encoded Genes of Salmonella Typhimurium Influence Differential Polarization of Porcine Alveolar Macrophages in Vitro. BMC Vet Res (2012) 8:115. doi: 10.1186/ 1746-6148-8-115

24. Hau SJ, Mou KT, Bayles DO, Brockmeier SL. Transcriptomic Differences Noted in Glaesserella Parasuis Between Growth in Broth and on Agar. PloS One (2019) 14:e0220365. doi: 10.1371/journal.pone.0220365

25. Howell KJ, Weinert LA, Luan S-L, Peters SE, Chaudhuri RR, Harris D, et al. Gene Content and Diversity of the Loci Encoding Biosynthesis of Capsular Polysaccharides of the 15 Serovar Reference Strains of Haemophilus Parasuis. J Bacteriol (2013) 195:4264-73. doi: 10.1128/JB.00471-13

26. Olvera A, Pina S, Pérez-Simó M, Oliveira S, Bensaid A. VirulenceAssociated Trimeric Autotransporters of Haemophilus Parasuis are Antigenic Proteins Expressed in Vivo. Vet Res (2010) 41:26. doi: 10.1051/ vetres/2009074

27. Ezraty B, Gennaris A, Barras F, Collet J-F. Oxidative Stress, Protein Damage and Repair in Bacteria. Nat Rev Microbiol (2017) 15:385-96. doi: 10.1038/ nrmicro.2017.26
28. Bedouhène S, Moulti-Mati F, Hurtado-Nedelec M, Dang PM-C, El-Benna J. Luminol-Amplified Chemiluminescence Detects Mainly Superoxide Anion Produced by Human Neutrophils. Am J Blood Res (2017) 7:41-8.

29. Wen Y, Wen Y, Wen X, Cao S, Huang X, Wu R, et al. Oxyr of Haemophilus Parasuis is a Global Transcriptional Regulator Important in Oxidative Stress Resistance and Growth. Gene (2018) 643:107-16. doi: 10.1016/j.gene. 2017.12.010

30. Kavanová L, Prodělalová J, Nedbalcová K, Matiašovic J, Volf J, Faldyna M, et al. Immune Response of Porcine Alveolar Macrophages to a Concurrent Infection With Porcine Reproductive and Respiratory Syndrome Virus and Haemophilus Parasuis in Vitro. Vet Microbiol (2015) 180:28-35. doi: 10.1016/ j.vetmic.2015.08.026

31. Li G, Xie F, Li J, Liu J, Li D, Zhang Y, et al. Identification of Novel Haemophilus Parasuis Serovar 5 Vaccine Candidates Using an Immunoproteomic Approach. J Proteomics (2017) 163:111-7. doi: 10.1016/j.jprot.2017.05.014

32. Guo L, Xu L, Wu T, Fu S, Qiu Y, Hu C-AA, et al. Evaluation of Recombinant Protein Superoxide Dismutase of Haemophilus Parasuis Strain SH0165 as Vaccine Candidate in a Mouse Model. Can J Microbiol (2017) 63:312-20. doi: 10.1139/cjm-2016-0671

33. Brockmeier SL, Register KB, Kuehn JS, Nicholson TL, Loving CL, Bayles DO, et al. Virulence and Draft Genome Sequence Overview of Multiple Strains of the Swine Pathogen Haemophilus Parasuis. PloS One (2014) 9(8):e103787. doi: 10.1371/journal.pone.0103787

34. Segal BH, Grimm MJ, Khan ANH, Han W, Blackwell TS. Regulation of Innate Immunity by NADPH Oxidase. Free Radic Biol Med (2012) 53:72-80. doi: 10.1016/j.freeradbiomed.2012.04.022

35. Zeng Z, Zhang B, He H, Chen X, Ren Y, Yue H, et al. Lgtf Effects of Haemophilus Parasuis LOS Induced Inflammation Through Regulation of NF- $\mathrm{kb}$ and MAPKs Signaling Pathways. Microb Pathog (2017) 110:380-4. doi: 10.1016/j.micpath.2017.06.035

36. Chen Y, Jin H, Chen P, Li Z, Meng X, Liu M, et al. Haemophilus Parasuis Infection Activates the NF- kb Pathway in PK-15 Cells Through Iкb Degradation. Vet Microbiol (2012) 160:259-63. doi: 10.1016/j.vetmic. 2012.05.021

37. Fu S, Liu H, Chen X, Qiu Y, Ye C, Liu Y, et al. Baicalin Inhibits Haemophilus Parasuis-Induced High-Mobility Group Box 1 Release During Inflammation. Int J Mol Sci (2018) 19:1307. doi: 10.3390/ ijms 19051307

38. Ulich TR, Guo K, Yin S, del Castillo J, Yi ES, Thompson RC, et al. EndotoxinInduced Cytokine Gene Expression in Vivo. IV. Expression of Interleukin-1 Alpha/Beta and Interleukin-1 Receptor Antagonist MRNA During Endotoxemia and During Endotoxin-Initiated Local Acute Inflammation. Am J Pathol (1992) 141:61-8.

39. Vannier E, Miller LC, Dinarello CA. Coordinated Antiinflammatory Effects of Interleukin 4: Interleukin 4 Suppresses Interleukin 1 Production But UpRegulates Gene Expression and Synthesis of Interleukin 1 Receptor Antagonist. Proc Natl Acad Sci USA (1992) 89:4076-80. doi: 10.1073/ pnas.89.9.4076

40. Jenkins JK, Malyak M, Arend WP. The Effects of interleukin-10 on Interleukin-1 Receptor Antagonist and Interleukin-1 Beta Production in Human Monocytes and Neutrophils. Lymphokine Cytokine Res (1994) 13:47-54. doi: 10.1007/BF01541172

41. Moore KW, O'Garra A, de Waal Malefyt R, Vieira P, Mosmann TR. Interleukin-10. Annu Rev Immunol (1993) 11:165-90. doi: 10.1146/ annurev.iy.11.040193.001121

42. Foey AD, Parry SL, Williams LM, Feldmann M, Foxwell BM, Brennan FM. Regulation of Monocyte IL-10 Synthesis by Endogenous IL-1 and TNF-alpha: Role of the p38 and p42/44 Mitogen-Activated Protein Kinases. J Immunol (1998) 160:920-8.

43. Aggarwal BB, Samanta A, Feldmann M. Tnf- $\alpha$. In: JJ Oppenheim, M Feldmann, SK Durum, T Hirano, J Vilcek, NA Nicola, editors. Cytokine Reference. A Compendium of Cytokines and Other Mediators of Host Defense, vol. 1. New York: Academic Press (2001). p. 413-34.

44. Fuente AJM de la, Ferri EFR, Tejerina F, Frandoloso R, Martínez SM Martín CBG. Cytokine Expression in Colostrum-Deprived Pigs Immunized and Challenged With Haemophilus Parasuis. Res Vet Sci (2009) 87:47-52. doi: 10.1016/j.rvsc.2008.12.012 
45. Reddy NR, Borgs P, Wilkie BN. Cytokine MRNA Expression in Leukocytes of Efferent Lymph From Stimulated Lymph Nodes in Pigs. Vet Immunol Immunopathol (2000) 74:31-46. doi: 10.1016/S0165-2427 (00)00164-1

46. Baggiolini M, Loetscher P, Moser B. Interleukin-8 and the Chemokine Family. Int J Immunopharmacol (1995) 17:103-8. doi: 10.1016/0192-0561(94)00088-6

47. Zhang H, Li L, Liu L. Fcyri (CD64) Contributes to the Severity of Immune Inflammation Through Regulating NF-Kb/NLRP3 Inflammasome Pathway. Life Sci (2018) 207:296-303. doi: 10.1016/j.lfs.2018.06.015

48. Aderem A. Phagocytosis and the Inflammatory Response. J Infect Dis (2003) 187:S340-5. doi: $10.1086 / 374747$
Conflict of Interest: The authors declare that the research was conducted in the absence of any commercial or financial relationships that could be construed as a potential conflict of interest.

Copyright $\odot 2021$ Matiašková, Kavanová, Kulich, Gebauer, Nedbalcová, Kudláčková, Tesarík and Faldyna. This is an open-access article distributed under the terms of the Creative Commons Attribution License (CC BY). The use, distribution or reproduction in other forums is permitted, provided the original author(s) and the copyright owner(s) are credited and that the original publication in this journal is cited, in accordance with accepted academic practice. No use, distribution or reproduction is permitted which does not comply with these terms. 